\title{
Saúde Reprodutiva
}

| Kenneth R. de Camargo Jr. |

As questôes ligadas à saúde reprodutiva das mulheres têm como horizonte comum a resistência a várias formas de dominação expressas nos sistemas de gênero de várias culturas. Poder decidir se querem ou não engravidar, se querem ou não levar a gestação a termo, e mesmo como se dará o parto ainda é privilégio de relativamente poucas mulheres dentre a população feminina mundial. Aspectos variados dessas questões são abordados nos artigos que compõem o tema desta edição, organizado a partir de artigos de livre demanda que já aguardavam publicação.

Abrindo o tema, Paiva e Brandão trazem uma revisão de literatura, nacional e internacional, sobre políticas de contracepção de emergência, com ênfase no papel das farmácias. Por sua vez, Cardoso apresenta os resultados de uma pesquisa qualitativa sobre o desencontro entre o desejo pelo parto vaginal e o desfecho em cesariana, com base na experiência de mulheres de camadas médias. Segue-se o artigo de Nunes com os resultados de estudo sobre a gravidez na adolescência, com adolescentes de camadas populares entre 16 e 18 anos de idade. Encerrando o tema, temos a descrição de Santos e Pereira das vivências de puérperas sobre a atenção recebida durante o processo parturitivo em uma maternidade pública de Feira de Santana (BA).

A seção de temas livres se inicia com o artigo de Alves e Escorel, que reveem o debate sobre pobreza como questão social na América Latina e a aproximação com os teóricos franceses da exclusão social. Segue-se a análise de Gawryszewski et al. sobre a política de hierarquização do SUS como mecanismo do planejamento, enfocando as práticas desenvolvidas nas Centrais de Regulação. Ainda tratando de temas ligados à gestão, Dwyer e Mattos discutem o potencial de prática de integralidade contido no Serviço de Assistência Móvel de Urgência (SAMU), com base em entrevistas com atores importantes da sua gestão. 
Cavalcante et al. estudaram como tem se dado o uso do apoio matricial como ferramenta do cuidado à criança com problemas de saúde mental na Estratégia de Saúde da Família. Ferreira e Espírito Santo, por sua vez, apresentam resultados de pesquisa sobre itinerários terapêuticos da população do complexo de favelas de Manguinhos, Rio de Janeiro (RJ). Na sequência, temos o estudo de Duarte et al., que identifica as características e os procedimentos diagnósticos e terapêuticos das internações pediátricas em hospitais do sistema público de saúde no município do Rio de Janeiro.

Mendonça e Camargo Jr. trazem um estudo da produção brasileira sobre o complexo médico-industrial, abordada pelo prisma dos estudos sobre ciência. Também com base em um corpo específico de literatura, Mello et al. fazem uma revisão terminológica de conceitos da área de biossegurança, com atenção para as dificuldades de comunicação tanto entre experts quanto com a opinião pública. Já o artigo seguinte, de Pazo e Aguiar, é baseado em pesquisa empírica, que analisa os significados de experiências de violência conjugal a partir de banco de dados resultante dos registros de um serviço telefônico anônimo, apoiadas na literatura feminista brasileira contemporânea.

Nascimento analisa o "Guia de Acompanhamento da Gestão Autônoma da Medicação em Saúde Mental”, da província do Québec (Canadá), propondo o que denomina "gestão compartilhada da medicação em saúde mental". Em outro artigo abordando um tema ligado à saúde mental, Oliveira discute a medicalização do risco para a psicose, ligada à construção de uma nova categoria diagnóstica pela força-tarefa de elaboração do DSM-5, a síndrome de risco para a psicose ou, mais recentemente, síndrome dos sintomas psicóticos atenuados.

Soares e Deprá retomam o debate sobre judicialização da saúde e acesso a medicamentos, enfocando as ligações entre a indústria farmacêutica e as associaçôes de pacientes. Outro aspecto ligado ao consumo de medicamentos é tratado por Araújo et al., que relatam o percurso histórico da regulação da propaganda de medicamentos no Brasil a partir dos principais marcos legais: a Junta Central de Higiene (1851), a Lei de Vigilância Sanitária (1976) e a criação da ANVISA (1999).

Garbin et al. realizaram revisão bibliográfica sobre promoção da saúde, informação e saúde na internet e exclusão digital, para discutir possibilidades e desafios na utilização da internet na promoção da saúde. Segue-se o artigo de Barros 
et al., sobre as representações sociais do consumo de carne em Belo Horizonte (MG), com base em entrevistas semiestruturadas com frequentadores do Mercado Central de Belo Horizonte, analisadas com a técnica de análise de conteúdo. Por fim, encerrando a seção de temas livres, Uchôa et al. discutem os avanços e desafios do trabalho em equipe multiprofissional na reabilitação infantil, com base em estudo de caso num centro de referência estadual em Natal (RN).

\section{Nota aos autores}

Ao longo dos últimos anos, começamos a observar uma tendência na elevação do número de autores por artigo. Ainda que justificável em muitos casos, esta por vezes se mostra questionável quando observamos as declarações de contribuição para a redação do artigo, e sobretudo quando as comparamos com o que foi realizado em termos de pesquisa. Acreditamos que isto se deva à falta de clareza, para muitos pesquisadores, sobre os critérios que caracterizam contribuição suficiente sobre autoria, especialmente em trabalhos que envolvem equipes de pesquisa.

Este é um dos temas que motivavaram o CNPq a criar um comitê encarregado de produzir um conjunto de normas para a garantia da integridade ética da pesquisa. Dentre estas, destacamos:

16: A inclusão de autores no manuscrito deve ser discutida antes de começar a colaboração e deve se fundamentar em orientações já estabelecidas, tais como as do International Committee of Medical Journal Editors.

17: Somente as pessoas que emprestaram contribuição significativa ao trabalho merecem autoria em um manuscrito. Por contribuição significativa entende-se realização de experimentos, participação na elaboração do planejamento experimental, análise de resultados ou elaboração do corpo do manuscrito. Empréstimo de equipamentos, obtenção de financiamento ou supervisão geral por si só não justificam a inclusão de novos autores, que devem ser objeto de agradecimento.

18: A colaboração entre docentes e estudantes deve seguir os mesmos critérios. Os supervisores devem cuidar para que não se incluam na autoria estudantes com pequena ou nenhuma contribuição nem excluir aqueles que efetivamente participaram do trabalho. Autoria fantasma em Ciência é eticamente inaceitável.

19: Todos os autores de um trabalho são responsáveis pela veracidade e idoneidade do trabalho, cabendo ao primeiro autor e ao autor correspondente responsabilidade integral, e aos demais autores, responsabilidade pelas suas contribuiçôes individuais.

20: Os autores devem ser capazes de descrever, quando solicitados, a sua contribuição pessoal ao trabalho. (http://www.cnpq.br/normas/lei_po_085_11.htm\#etica - consultado em 05/01/2011). 
Lembramos aos autores que devem encaminhar as declaraçôes de autoria juntamente com o manuscrito, conforme as normas da revista e tendo em vista as determinações supracitadas, especificando a contribuição de cada autor em detalhes, especialmente nos artigos com número elevado de coautorias. Os editores se reservam o direito de avaliar a adequação das declaraçôes às normas vigentes, e a partir desta edição passaremos a publicar a informação sobre contribuição de autoria juntamente com o artigo, para garantir o máximo de transparência possível.

$$
* * *
$$

\section{Partidas e chegadas}

A partir deste número, Physis não conta mais com a participação de Eduardo Faerstein como editor associado, em função de sua opção por se dedicar a novos projetos, que certamente serão bem-sucedidos; independentemente disso, desejamos sucesso nessa nova etapa. Gulnar Azevedo e Silva, também do IMS/ UERJ, irá substituí-lo na tarefa. Por outro lado, registramos novas chegadas: dada a elevada oferta de artigos que temos recebido, consideramos necessário expandir nosso time editorial, incluindo também colegas de outras instituições que não a UERJ. Damos boas vindas a Miriam Ventura, do IESC/UFRJ, Aluísio Gomes da Silva Jr., do ISC/UFF, e Octavio Bonet, do IFCS/UFRJ, a quem agradecemos a disponibilidade em prontamente atender ao nosso convite. Aproveitando a ocasião, estendemos as boas-vindas também a Victor Ribeiro, que desde o ano passado vem reforçando a equipe de produção da revista. 